Journal of Teacher Education for Sustainability, vol. 13, no. 1, pp. 5-18, 2011

\title{
ENGAGING LEARNERS IN COOPERATIVE LEARNING THROUGH ENVIRONMENTAL AND CROSS-CULTURAL ACTIVITIES
}

\author{
Soula Mitakidou and Konstantia Tamoutseli \\ Aristotle University of Thessaloniki, Greece
}

\begin{abstract}
There is a definite intersection of targets and intentions between education for sustainable development (ESD) and cross-cultural education (CCE), since both ESD and CCE aspire to pursue and develop values such as equity, democracy and quality of life in a multicultural setting. Apart from their common philosophical basis, ESD and CCE endorse similar teaching methods, i.e. experiential and cooperative learning, and pursue the development of abilities such as research interest, critical thought and political awareness, with the intention to develop a learning community intrinsically connected with the wider community and society. This study aspires to explore the possibilities of cooperative learning to effectively promote the aims of both ESD and CCE. The children of a public school in Thessaloniki, Greece, were involved in this action research related to their local environment. The methodological tools used included walk mapping and landscape analysis charts combined with environmental assessment sheets. The ensuing discussion facilitates reflection on the prospects of cooperation in a class with a mixed ability population.
\end{abstract}

Key words: cooperative learning, education for sustainable development, cross-cultural education

\section{Introduction}

The effectiveness of cooperative learning in relation to more traditional forms of teaching has been amply researched and theoretically explored for several decades now (Matsagouras, 1987; Sharan \& Sharan, 1992; Slavin, 1995; Haralambous, 1996, 2000; Johnson \& Johnson, 1998). The model of cooperative learning has taken the form of an organized educational movement that promises better learning results. Research studies have shown that, among other benefits, it facilitates the development of thought and socialization of young children and it contributes to better educational management of diverse school populations (Cohen, 1994; Stavridou, 1999). 
In the framework of cross-cultural education, an abundance of research findings have confirmed the efficiency of cooperative learning in organizing mixed ability, multicultural classes (Sharan \& Sharan, 1992; Kagan, 1994; Slavin, 1995). As Sharan and Sharan (1992) point out, "since their inception, cooperative learning methods have been directed at creating positive conditions for effective instruction and social integration in the ethnically heterogeneous classroom. Classroom learning conducted with cooperative small groups of students provides a social setting conducive to the development of friendly relationships among students from different ethnic and social group" ( p. 143). Cooperative classroom organization contributes to the enhancement of children's self-esteem and the development of harmonious interpersonal relationships, without impeding the cognitive performance of any group of students. On the contrary, it enhances the development of high order abilities, such as problem solving, decision making, critical thinking and assessment (Slavin, 1995).

Similarly, the significance of cooperative learning is stressed as a basic component of all teaching techniques proposed by the education for sustainable development (Skoullos \& Malotidi, 2004) and as one of the best methods for its successful application (Ghosh, 2009). The Report of the International Committee of UNESCO for education in the 21 st century has declared that the third pillar of education is that children learn to coexist and cooperate (UNESCO, 1998). Abilities promoted by education for sustainable development, such as decision making, conflict management, initiative for action, personal and social communication abilities and the development of mutual trust and acceptance of difference, may flourish through cooperative learning (Ghosh, 2009). Cooperative learning, then, is high on the agenda of both CCE and ESD, since research has shown that children achieve better performance through cooperation (Haralambous, 1996), develop positive attitudes to school, learn to respect their classmates and sustain quality interpersonal relationships (Johnson \& Johnson, 1998).

In the Greek context, where teacher-centred teaching is deep-rooted, cooperative learning was part of the innovative curriculum that the Ministry of Education has been trying to introduce since 2003 (Alahiotis, 2003). However, the most difficult part in introducing an innovation in education is its application, as research studies have demonstrated that teachers are reluctant to attempt innovation; they usually raise significant or insignificant obstacles to its use (Fullan, 1993; Hargreaves, 1995). This may be the main reason why, despite positive results of its application, cooperative learning has not been adopted and established in class, as it requires that both teachers and students embrace new roles and responsibilities (Rogoff, 1994). Teachers need to be persuaded of the need to change their teaching practice and be allowed the chance to acquire the knowledge so that the idea of transformation matures in them and motivates a change of attitudes (Connelly \& Clandinin, 1988). This coupled with the fact that the Greek educational system, despite progressive announcements, remains centrally controlled and based on a strict, uniform curriculum makes change a hard and complex process.

With this study, the authors attempted to explore the option of promoting cooperative learning in a diverse classroom through topics related to sustainable and cross-cultural education. This study is part of a wider ongoing research that examines if and how in-service training on sustainable and cross-cultural education that suggests significant changes in teachers' and students' roles affects the teaching methods of teachers. 


\section{The study}

\section{Research field}

The study was conducted at a public primary school in Toumba, Thessaloniki, Greece. The group of participants included 25 nine years old children, comprising a whole fourth form. Eighteen children of the class were boys; seven children were girls. The class included seven children of immigrant families and one boy with mental disability and mobility difficulties. Toumba is a densely populated area of Thessaloniki. The school population consisted exclusively of neighbourhood children, an element that facilitated the topic selection of the study, i.e. "My neighbourhood".

The authors were intrigued to conduct the study when, on visiting the school for the needs of the wider research, they realized that, despite the fact that the school accommodated children of diverse cultural and linguistic backgrounds and also despite the fact that it was a school open to the local community and all kinds of educational innovation, the traditional frontal teaching model prevailed over the cooperative. The school principal enthusiastically endorsed the study and was keen on playing the role of cooperating teacher in planning and implementing it in cooperation with the researchers (the two authors). Therefore, the study took the form of action research, i.e. it was a short-scale participatory and collaborative intervention that generated discussion and reflection among participants on the possibilities of cooperation for increasing student participation and achievement. It occupied 12 hours (four 3-hour sessions) in the span of four weeks during "flexible zone", a time designated, according to the curriculum, for innovative activities and interdisciplinary projects. The cooperating teacher was responsible for the flexible zone session (3 hours weekly) in the class of the study. Even though the flexible zone is included in the timetable of each school, in reality, most teachers use this time for catching up on regular school work and consolidation of the taught syllabus. This was true for the class of this study, as well.

\section{Aim}

This study is aimed at exploring:

- the children's views on cooperative learning;

- the influence of cooperative work on a class accustomed to traditional teaching modes and, therefore, the possibility of change of the children's views towards cooperative work through their active participation in their own learning;

- the possibility of change of the children's views towards the inclusion of children of minority groups;

- how a class intervention and the possible change it brought about in the teachers' views and attitudes could serve as a model for school-based teacher training;

- children's sensitization to the environmental problems of their neighbourhood;

- the development of harmonious and equitable relationships between children with diverse cultural origin; 
- $\quad$ how educational techniques introduced for CCD and ESD and used for teaching topics related to local issues can motivate children's participation in cooperative learning activities.

\section{Research planning and procedure}

At the onset of the study, a questionnaire was distributed to the students intended to explore their views towards cooperation and group work and their previous experience with it. After completing the questionnaire, the students were involved in a discussion on the merits of cooperation in class and, eventually, they were asked to be divided into groups of five. This process proved more difficult than anticipated as children had a lot of difficulty deciding the scheme of groups. It took two whole teaching hours, a lot of discussion and a range of interventions on the teacher-researcher's part, such as role play, for instance, to sensitize children, make them bring themselves into the position of undesirable members of the groups to accept their teacher's suggestion for the makeup of groups. The cooperating teacher's main intention was to create groups of students based on cultural diversity and differentiation as to their needs, abilities and skills so that the classroom atmosphere could aim at acceptance of every group member's individuality (Nichols, 1996).

The class with the cooperating teacher decided on the topic of the project. The chosen topic was "My neighbourhood." As supported by ESD, sensitization on problems of the local environment is a prerequisite if interest is to be gradually extended to topics of the wider regional and global environment (Shallcross, Robinson, Pace, \& Wals 2006). Choosing familiar places to have children involved in the observation, identification and promotion of problems related to these places and encouraging them to make suggestions for their amelioration facilitates the attraction and maintenance of interest on their part. Moreover, this process not only contributes to children's gaining an awareness of place value and skills, but it also develops attitudes of active citizenship, all traits promoted by both CCD and ESD. According to Orr (2005), the study of space in education is very important as it constitutes the basis for sensible coordination and planning of space. It involves children in direct observation, research and experimentation and helps them turn theory into practice.

At the onset of the project, children changed the layout of their classroom to facilitate working in groups. The brainstorming technique was used to stimulate children's interest on the topic of their neighbourhood and to expose their prior views and sentiments about it. The cooperating teacher asked the children to use first adjectives and then nouns to express their feelings about their neighbourhood. All nouns and adjectives suggested by the children were written on the board. In the discussion that followed, children were asked to justify their choices of words. Then, the adjectives and nouns were classified in two columns on the board: one column was entitled social issues and the other environmental issues. The words were further classified into negative and positive thus creating two sub-columns for each of the original columns. The ensuing discussion focused on the causes of negative characteristics and the interrelation between social and environmental issues.

In the subsequent sessions, children cooperated in their groups to complete a twocolumn table with all the things they would like and they would not like in their neighbour- 
hood. A short presentation of the table of each group was made by an elected member of the group. Through whole class discussion and reflection, the cooperating teacher finalized and wrote on the board a comprehensive list of all the children's views. Then each group of children was given two sheets with the "diamond" provided in Figure 1. The children were also given the nine statements from the two columns they themselves had produced to delineate their likes and dislikes in their neighbourhood. The children had to cooperate and agree on how they should rank their likes and dislikes in each one of the diamonds. The children eagerly cooperated to prioritize their preferences and complete the two diamonds one for their likes and one for their dislikes ranking them in ascending order on the two separate diamonds.

The diamond is a useful technique for getting someone to locate and demonstrate their priorities; encouraging pupils to cooperate with an aim to take a decision, make a selection, etc.; developing skills like listening, defending, questioning, comparing, judging and evaluating. The prioritising involved in making the "diamond" requires a range of evaluative and discussion skills, such as clarifying and expressing values, motivating and taking action (Shallcross, 2004).

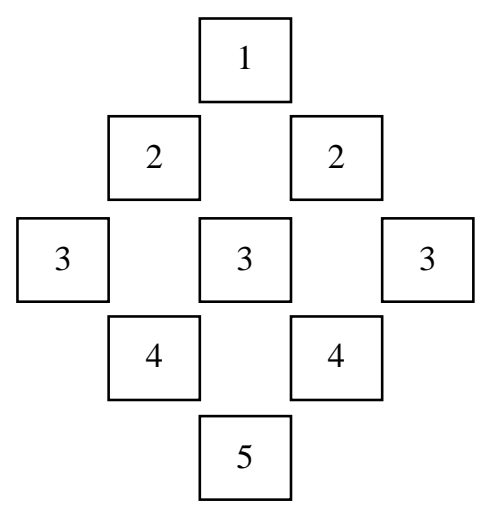

Figure 1. Evaluation diamond

Each group's ratings were presented by the group's representative and, in the discussion that followed, the similarities and differences in the groups' choices were discussed. Through discussion, an effort was made so that all groups would agree on two common diamonds, one for the positive and one for the negative characteristics. Agreement on common ratings and choices in the diamonds was accomplished on the basis of frequency of appearance of each characteristic in all groups.

The characteristics chosen by children as the most desirable for their neighbourhood were cross-examined through drawings the children drew at home, so that they would not be influenced by one another. Children's drawings have traditionally been used as a tool through which children represent and come to terms with their feelings (Roberts-Holmes, 2005). Eliciting their representations of their desired neighbourhood through drawing is a very common activity for children of this age (Lewis \& Greene, 1983). Moreover, by draw- 
ing, children are given more time to express themselves compared to the quick responses an oral discussion demands, thus probable language difficulties are overcome (Chambers, 1983). As Crook (1985) maintains, the content of children's drawings may offer information on children's feelings for the world. Children's drawings may be windows to children's thoughts and feelings, mostly because they reflect a picture of their mind (Thomas \& Silk, 1992). The children's drawings depicted their ideal picture of their neighbourhood. The authors classified the various elements included in the children's drawings in two categories: natural (for instance, trees, flowers and grass) and manmade (for instance, houses, cars, roads) and evaluated them on the basis of quantitative data, i.e. their frequency and the space they occupied in the drawings (Cronin-Jones, 2005).

Analysis of these data revealed that nature (trees, flowers and grass) had a prominent place in the children's desired picture of their neighbourhood, considering that it occupied two thirds of the space in most drawings. The wish for a more humane residence with green at the entrance and balconies came second in the children's preferences, closely followed by the desire for pets and playgrounds. Overall, the children's drawings included all of the characteristics that they rated as the most important for their desired neighbourhood during group activities and discussion in class.

A whole hour of a teaching session was dedicated for the class to formulate cards with indices of environmental assessment on the basis of their discussions and activities on the desired characteristics of their neighbourhood and their relation to the quality of life. In the rest of the teaching session, pairs of children were given a map of the area and the cards with the indices of environmental evaluation. The cooperating teacher suggested a route of study and mapping of the field, and the children located the route on their maps so that they could follow it easily.

The children participated with enthusiasm in the field study; they worked harmoniously in groups of three and there was a lot of intergroup discussion throughout the route. They exhibited excellent observation skills, and they critically commented on and accurately recorded their findings. One group of children were given digital cameras to take photos during the field study. Using cameras is an engaging strategy for children and their photographs are likely to reflect their interests and concerns (Cook \& Hess, 2007).

Table 1. Card of environmental assessment

\begin{tabular}{|c|c|c|c|c|}
\hline Characteristic/evaluation & Very good & Good & Mediocre & Bad \\
\hline \multicolumn{5}{|l|}{ Houses } \\
\hline \multicolumn{5}{|l|}{ Trees } \\
\hline \multicolumn{5}{|l|}{ Means of transportation } \\
\hline \multicolumn{5}{|l|}{ Pedestrian streets } \\
\hline \multicolumn{5}{|l|}{ Bicycle trails } \\
\hline \multicolumn{5}{|l|}{ Playgrounds } \\
\hline Parks & & & & \\
\hline
\end{tabular}

Sequel to Table 1 see on $p .11$. 


\begin{tabular}{ll}
\hline Cleanliness & Sequel to \\
\hline Streets & \\
\hline Sound pollution & \\
\hline Side walks & \\
\hline Ramps for the disabled
\end{tabular}

In the final teaching session, children's photos were projected in the classroom; there was a class discussion on neighbourhood images shown in the photos. The children's findings were analysed, and views were expressed for the reasons, the responsibilities - personal and collective - as well as the governmental liability for the current situation. The children cooperated in their groups to come up with a group list, which they presented in class in order to formulate a collective list where the various categories of responsibility (personal, collective, governmental) were classified. At the end of this session, the children created a personal plan of action, the application of which demanded their family's contribution.

The children then discussed in class their experience from participating in the project. In the end, a new questionnaire was distributed to the children aiming at recording their views regarding their experience from working in groups.

\section{Findings}

Analysis of the two questionnaires addressed to pupils, before and after the intervention, revealed that working in groups was not a usual teaching routine in this class. The children acknowledged that individual work was the only way of carrying out tasks in their class. Discussion with the class teacher confirmed the children's statements, as he claimed that he never organized his class or planned activities in ways that favoured group work. It is interesting to notice that most children expressed a preference for group work before the intervention and gave good explanations to justify their preference, despite the fact that they had little experience of group work.

The development of good relationships, enjoyment in working with friends and giving and receiving help are all assets characterizing cooperative learning, according to the children. The students thought that, by working in groups, work became a joyful play, and they liked the fact that different ideas were expressed and taken into consideration: "Work becomes a joyful play, and we suggest different ideas"; "They [peers] give me new ideas, and I have a good time"; "They may know something I don't know". The children found problem solving became easier when working with other children: "I find solutions easier along with other children"; "They [peers] help me when I get stuck".

With reference to the criteria according to which they chose group members, the first was the gender (nine boys; five girls), followed by friendship, mostly for boys (five boys; one girl). The criteria suggested by the children for the formulation of groups coupled with the usual teacher-centred organization of teaching explain the difficulties the cooperating teacher encountered in creating groups.

In-class observation showed that the children willingly participated in all activities related to the project. In the first session, intending to stimulate the children's interest for the selected topic when the children were asked to describe their neighbourhood, they mostly 
used positive characteristics (for instance, amazing, good, green, love, pleasure), probably attributed to the children's emotional relationship with their neighbourhood. In the discussion that followed, however, they could not justify their characterizations, so social and developmental problems started to emerge.

Green (trees, bushes, flowers) houses, parks, playgrounds, parking space, quiet, pets, large open spaces were common preferences among all groups of children. One of the groups added their preference for a theatre, a cinema and a bicycle trail. The numerous cars, traffic jams, sound pollution, the occupancy of sidewalks by cars, vandalisms, disputes and rows, trash, filth and pollution were the characteristics of their neighbourhood they disliked.

The preferred image of the neighbourhood as it emerged from the children's drawings included mainly homes, large streets, lots of trees, a lot of green, flowers, playgrounds and no cars. It was impressive that only one picture showed a car, which was parked in a designated parking space. Apartment buildings appear in only two of the drawings.

Examination of the classification in evaluation diamonds revealed that "green" and "trees" occupy the top of children's choices, with "pets" being the second and "parks" being the third most chosen preferences. The other choices that are diversified in the children's ratings but appear in all four diamonds are "open spaces," "playgrounds," "peace and quiet." Concerning the negative characteristics of the neighbourhood, "pollution" and "sound pollution" are placed at the top in all ratings. In lower ratings, follow "traffic jams," "vandalisms," "quarrels" and "trash".

The children demonstrated great interest for the field research. They asked for more time on the field but school regulations did not allow extension of time. During the field trip, they completed the environmental evaluation cards very carefully and their comments in the walk mapping were accurate and critical.

In their evaluation of the project, the children described as "very positive" the fact that they observed things they had not seen before: the garbage outside buckets, the scarcity of buckets, the broken sidewalks, the cars parked on sidewalks, the lack of green, the narrow sidewalks, the lack of trails for the blind and people with mobility difficulties, the pollution, the lack of bicycle trails, the narrow streets, the lack of green and flowers in the balconies, the trunks of cut trees, the ugly buildings. As a result of their walk and the discussion that followed in class, the children decided to put together a list of actions, both personal and family, as well as to write and address a letter to the local authorities in an effort to contribute to improving their environment.

Decisions in groups were reached with relative ease. All views were voiced and considered with respect. The group presentations were followed by everyone with great interest and attention. The seven immigrant children also participated very willingly, they were eager to present their views and comments and were included by their peers in all activities. It should also be stressed that the children tried to include the child with disabilities in all the activities, something that we were told had not happened previously.

The children's views regarding cooperation were recorded in the final questionnaire but there was also a final discussion where the children were invited to assess the experience of their participation in the study, their opinion about the types of activities as well as their work in groups. The children's reactions to all fields of inquiry were very positive. Without exception, all children embraced cooperative work and expressed their wish for 
this teaching scheme in all school subjects. Their justifications for their preference in the questionnaires included:

"I would love us to work in groups because we learn that way".

“...because we had no disputes".

"...because we had a wonderful time and we liked it".

“...because I collaborated with friends".

"...because we were together".

"...because we helped each other".

Similar views were expressed in the final discussion in class:

"We liked this way of working very much, we would like to repeat it".

"Our teacher rarely encourages us to work this way. It's always subject after subject, homework after homework. We rarely have a chance to discuss among us. We sometimes place our desks in a I class arrangement but even then we are not asked to work in groups".

"We had some difficulty in reaching an agreement at the beginning but, at the end, we managed to agree and had an excellent result”.

The authors asked the teachers of the school to complete questionnaires expressing their views on cooperative learning. Open-question questionnaires were distributed to the teachers by the cooperating teacher. Questionnaires were chosen so that teachers could feel free to express their views. Half of the teachers agreed to complete the questionnaire. The ones that refused justified it by saying that there was no reason to waste time for something that is inapplicable in the Greek school. Their negative attitude can be explained on the basis of the structure and organization of the Greek school that is completely centralized, traditional and teacher oriented. This is parallel to findings in other research studies mentioned above (Fullan, 1993; Hargreaves, 1995).

All of the teachers that completed the questionnaire claimed that cooperative learning was superior to teacher-centred instruction. Some of the advantages of cooperative learning they offered included children's socialization, the development of positive relations, mutual respect, solidarity and acceptance among children. Interestingly, all these advantages are related to psychosocial rather than cognitive development. Only one of the teachers referred to the advantage of building internal motivation for learning and respect for the school. These views correspond to the views expressed in two wider research studies among Greek teachers (Piliouras, Kokkotas, Georgiou, \& Nikolaou, 2002).

Despite their positive attitude to cooperative learning, the teachers who responded to the questionnaire admitted that they hardly ever used it. Their reasons for this distinct discrepancy between theory and practice were in a descending order: 1) the suffocating curriculum ("curriculum and school schedule are very strictly structured"); 2) the load of syllabus and the time restrictions that allow no time for such approaches to learning ("you cannot catch up with the syllabus," "such approaches stop you from running to catch up with the programme"); 3) difficulty in assessing children in the various subjects individually 
("sometimes the teacher makes erroneous judgments on the students' abilities") and 4) loss of control in class management ("too much noise," "a lot of commotion in class").

The school principal and our collaborator in carrying out the intervention claimed to be a "big fan of cooperative learning", but she also admitted that she rarely found herself able to use it for the same reasons that school teachers mentioned, adding also reasons related to the basic education of pre-service teachers and the in-service training of in-service teachers, and the parents and children's attitudes to teaching and learning. The school principal thought that "even new teachers do not work cooperatively, not because they are assimilated by the system but because their basic education does not prepare them effectively"; "old teachers need in-service training on cooperative learning techniques". The school principal continued by saying that "even children lack the education, they act individually, they are reluctant to cooperate in class"; "parents fear that cooperative learning is against their children's best interest, especially the parents of 'good' students. I have been an educator for 30 years, but I have not met a parent who is in favour of cooperative learning".

The principal's interpretations for the minimal application of cooperative learning in this school is directly related to the findings in research studies that highlight the need expressed by teachers to feel confident in order to attempt innovations in their practice (Piliouras, Malamitsa, Theodoridou, Fisfi, \& Kokkotas, 2000).

This need is confirmed in a comparative study between Greek and Cypriot teachers related to the application of cooperative learning in the teaching of science. The study demonstrated a significant difference between the two groups of teachers, with Cypriot teachers applying cooperative learning in their teaching due to their frequent participation in inservice teacher training programmes (Piliouras et al., 2002).

The cooperating teacher asserted that collaboration with the two researchers through a practical in-class application consolidated her confidence in her abilities to use cooperative learning. She confirmed that ESD and CCE activities carried out in the flexible zone, where there are no strict curriculum restrictions, may help the teacher realize and be persuaded about the efficacy of cooperative learning and thus decide to apply it across the curriculum.

\section{Concluding remarks}

This study took place in a school that is very active in a large range of programmes and innovative educational incentives but with a steady inclination for traditional teaching and learning arrangement. The results confirmed the appeal of cooperative learning among children. An interesting finding was also that through properly designed ESD and CCE projects, schools, apart from giving young children opportunities to explore, engage, connect with and contribute to their local community a range of experiences, skills and talents, can also effectively promote the development of cooperative learning, an approach to learning valued by both teachers and children. To overcome the difficulties in practical application, as they were pinpointed by teachers, school-based research projects can prove functional.

In addition, this study demonstrated the significance of school-based in-service training and two-way teacher-researcher cooperation in applying interventions. The small range 
of the intervention limits the prospects of generalizing findings. However, there is ample evidence in the relevant bibliographical literature that supports the effectiveness of cooperative learning especially in primary classes like the one of our study (Matsagouras, 1987; Sharan \& Sharan, 1992; Slavin, 1995; Johnson \& Johnson, 1998).

The topic of this study was closely associated with the children's immediate environment, so it motivated their interest. At the same time, through research of their immediate environment, the children demonstrated a sense of shared responsibility skills. Shared responsibility skills will enable them to recognize the importance of their participation in local, national and even global environmental decisions (Hart, 1997).

The lack of competition and formal assessment facilitated learning in groups, so the children worked together in harmony. They became familiar with new communication, observation and evaluation skills, critical thinking and decision making skills; they took initiatives and planned to take action. Equal participation in all activities was another positive outcome of the intervention, when compared with the difficulty the cooperating teacher faced to place children in groups at the beginning. That initial difficulty revealed covert biases on the children's part, but cooperation helped come to the surface and was deconstructed. The teaching techniques employed for involving the children, the topic that focused on the quality of neighbourhood life proved interesting for all the children regardless of ethnic, social cultural origin. This contributed to overcoming initial difficulties and children's willingness to cooperate came as a natural development.

The children's views of their neighbourhood and their visions of its future development are quite interesting. Through techniques such as brainstorming, dialogue, study and mapping of the field and evaluation the children identified with great accuracy the basic problems that hurt the quality of everyday life in their neighbourhood and in neighbourhoods in all major cities in Greece. Problems such as lack of green spaces, the bad condition of streets, sidewalks and public areas, the multiple pollution of the atmosphere, the dominance of the car, the lack of cleanliness and tidiness harm the children's everyday life. Equally interesting were the children's conclusions as to the distribution of responsibilities and their suggestions in the form of individual or collective plans of action for improving the conditions of living in their neighbourhood. The choice of topic that concerned the immediate environment of children helped them realize the need for cooperative and participatory activities for improving their quality of life not only at the school but also at the social level. This constitutes a common approach in most ESD programmes that focus on closing the gaps between knowledge and attitudes aiming at the development of active citizens (Shallcross, Robinson, Pace, \& Tamoutseli, 2007). Education can empower pupils by equipping them with the skills they need to assist schools and their local communities to become more sustainable (Defs, 2006).

This research confirms the importance of cooperation for equal participation of all children in the learning process and reveals the need for its systematic promotion at all levels of the educational praxis. A welcome development could be the cooperation among student teachers, their university supervisors and classroom practitioners in the framework of CCE and ESD cooperative projects that, among other benefits, would serve as a model of cooperation for children. This substantiates the need for a change of the overly structured 
curriculum that limits initiatives for creative development of a school programme, so that the school caters to the multiple needs and possibilities of all children.

\section{References:}

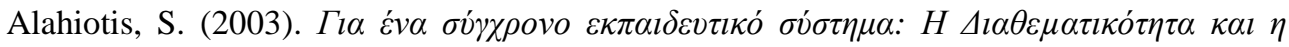

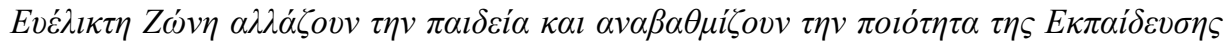
[For a contemporary educational system: The cross-thematic approach and the flexible zone changing education and upgrading its quality]. Retrieved December 16, 2010, from http://www.pischools.gr/download/programs/depps/s_alax_diathematikotita.pdf

Chambers, D. W. (1983). Stereotypic images of the scientist: The draw-a-scientist test. Science Education, 67(2), 255-265.

Cohen, E. (1994). Designing groupwork. New York: Teachers College Press.

Connelly, F. M., \& Clandinin, D., J. (1988). Teachers as curriculum planners: Narrating of experience. New York: Teachers College Press, Columbia University.

Cook, T., \& Hess, E. (2007). What the camera sees and from whose perspective: Fun methodologies for engaging children in enlightening adults. Childhood, 14(1), 29-45.

Crook, C. (1985). Knowledge and appearance. In N. H. Freeman \& M. V. Cox (Eds.), Visual order: The nature of development of pictorial representation (pp. 268-245). Cambridge: Cambridge University Press.

Cronin-Jones, L. L. (2005). Using drawings to assess student perception of schoolyard habitats: A case study of reform-based research in the United States. Canadian Journal of Environmental Education, 10, 225-240.

Department of Education and Skills (DfES). (2006). Communities and the environment: Government response to the consultation on the sustainable schools strategy. London: DfES.

Fullan, G. M. (1993). The new meaning of educational change. New York: Cassell.

Ghosh, N. (2009). Sustainable development through cooperative learning. In G. Siemens \& C. Fulford (Eds.), Proceedings of World Conference on Educational Multimedia, Hypermedia and Telecommunications 2009 (pp.1704-1709). Chesapeake, VA: AACE. Retrieved August 29, 2010, from http://www.editlib.org/p/31707/ editlib.org

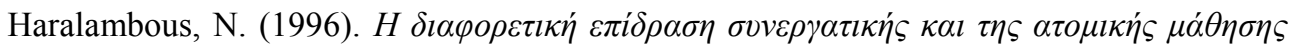

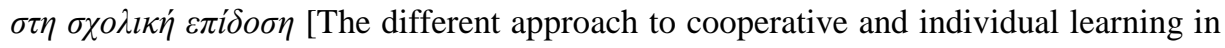

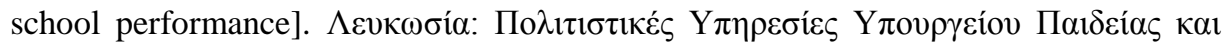

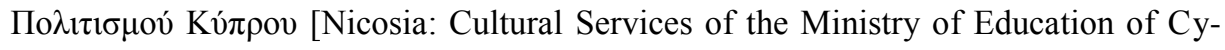
prus].

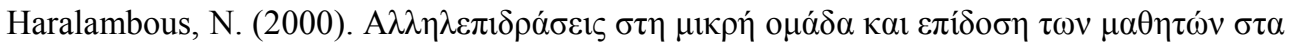

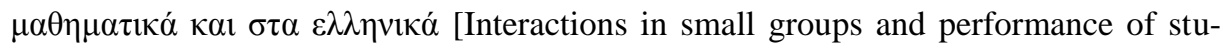
dents in mathematics in Greek]. П $\alpha \_\alpha \gamma \omega \gamma \iota \kappa \eta ́ ~ E \pi \imath \theta \varepsilon \omega ́ \rho \eta \sigma \eta$ [Educational Review], 30, 235-252.

Hargreaves, A. (1995). Changing teachers, changing times. London: Cassell.

Hart, R. (1997). Children's participation: The theory and practice of involving young citizens in community development and environmental care. London: UNICEF/Earthscan. 
Johnson, D. W., \& Johnson, R. T. (1998). Learning together and alone (5th ed.). Boston: Allyn \& BaconLe.

Kagan, S. (1994). Cooperative learning. San Clemente, CA: Kagan Publications.

Lewis, D., \& Greene, J. (1983). Your child's drawings: Their hidden meanings. London: Hutchinson.

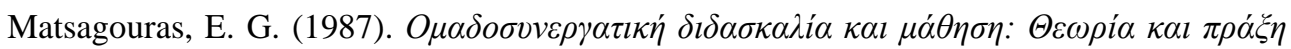

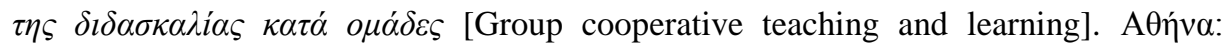

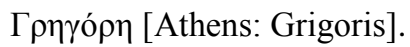

Nichols, J. D. (1996). Cooperative learning: A motivation tool to enhance student persistence, self regulation and efforts to please teacher and parents. Educational Research and Evaluation, 2(3), 246-260.

Orr, D. (2005). Place and pedagogy. In M. Stone \& Z. Barlow (Eds.), Ecological literacy: Educating our children for a sustainable world (pp. 85-95). San Francisco: Sierra Books.

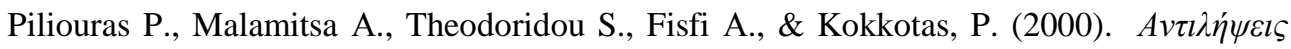

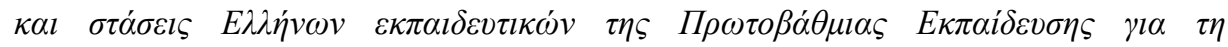

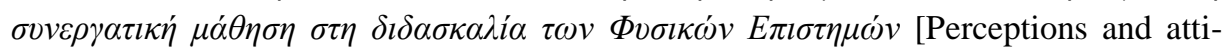
tudes of Greek primary school teachers to cooperative learning and teaching science]. Retrieved March 27, 2010, from http://www.primedu.uoa.gr/sciedu/old/resoursches/sta seis.pdf

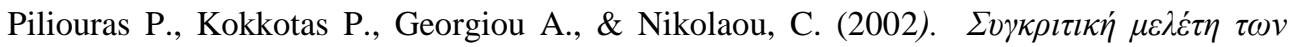

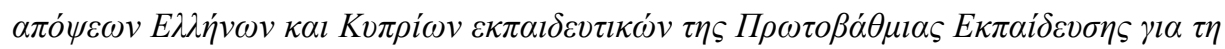

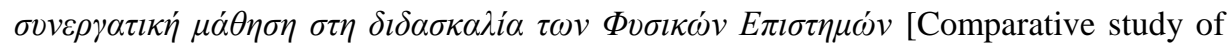
Greek-Cypriot primary school teachers' ideas on cooperative learning]. Retrieved March 27, 2010, from http://www.primedu.uoa.gr/sciedu/old/resoursches/cyprous.htm

Roberts-Holmes, G. (2005). Doing your early years' research project: A step-by-step guide. London: Sage Publications.

Rogoff, B. (1994). Developing understanding of the idea of communities of learners. Mind, Culture and Activity, 4, 209-299.

Shallcross, A. (2004). School development through whole school approaches to sustainability education: The SEEPS project. Manchester: Metropolitan University

Shallcross, T., Robinson, J., Pace, P., \& Wals, A. (2006). Creating sustainable school environments. Stoke on Trent, UK: Trentham Books.

Shallcross, T., Robinson, J., Pace, P., \& Tamoutseli, K. (2007). The role of students' voices and their influence on adults in creating sustainable environments in three schools. Improving Schools, 10(1), 72-84. Retrieved October 1, 2007, from http://www.sagepubli cations.com

Sharan, S., \& Sharan, Y. (1992). Expanding cooperative learning through group investigation. New York: Teachers College Press.

Skoullos, M. \& Malotidi, V. (2004). Handbook on methods used in environmental education - education for sustainable development. Athens: MIO-ECSDE.

Slavin, R. E. (1995). Cooperative learning: Theory, research, and practice (2nd ed.). Boston: Allyn \& Bacon. 


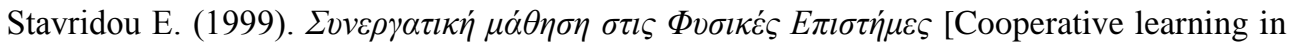

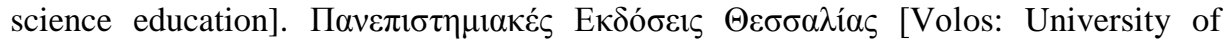
Thessaly Publications].

Thomas, G., \& Silk, A. (1992). An introduction to the psychology of children's drawings. Oxford: Harvester Blackwell.

UNESCO. (1998). Education for the twenty-first century: Issues and prospects. Paris: UNESCO.

\section{Correspondence:}

Dr Soula Mitakidou, School of Elementary Education, Faculty of Education, Aristotle University of Thessaloniki, 54124 Thessaloniki, Greece. Email: smitakid@eled.auth.gr 